\title{
Carreau Model for Liquid Thin Film Flow of Dissipative Magnetic-Nanofluids over a Stretching Sheet
}

\author{
C. Sulochana* and G.P. Ashwinkumar \\ Department of Mathematics, Gulbarga University, Kalaburagi-585 106, India. \\ math.sulochana@gmail.com
}

\begin{abstract}
In recent days, external magnetic fields are very effective to set the thermal and physical properties of magnetic-nanofluids and regulate the flow and heat transfer characteristics. The strength of the applied magnetic field affects the thermal conductivity of magnetic-nanofluids and makes it aeolotropic. With this incentive, we investigate the flow and heat transfer characteristics of electrically conducting liquid film flow of magnetic-nanofluids over a stretching sheet by considering the aligned magnetic field with space and temperature dependent heat source/sink, viscous dissipation and thermal radiation. For this study, we considered $\mathrm{Fe}_{3} \mathrm{O}_{4}$ and $\mathrm{CoFe}_{2} \mathrm{O}_{4}$ nanoparticles embedded in water. Numerical results are determined by adopting Runge-Kutta based shooting technique. Graphs are exhibited and explained for various parameters of interest. The influence of pertinent parameters on reduced Nusselt number, friction factor, flow and heat transfer is discussed with the assistance of graphs and tables. It is found that aligned magnetic field regulates the momentum boundary layer and heat transfer rate. It is also observed that increasing the volume fraction of nanoparticles effectively enhances the thermal conductivity of $\mathrm{Fe}_{3} \mathrm{O}_{4}$-water nanofluid when compared with $\mathrm{CoFe}_{2} \mathrm{O}_{4}$-water nanofluid.
\end{abstract}

Keywords: film flow, inclined magnetic field, viscous dissipation, radiation, nonuniform heat source/sink

\section{Nomenclature}

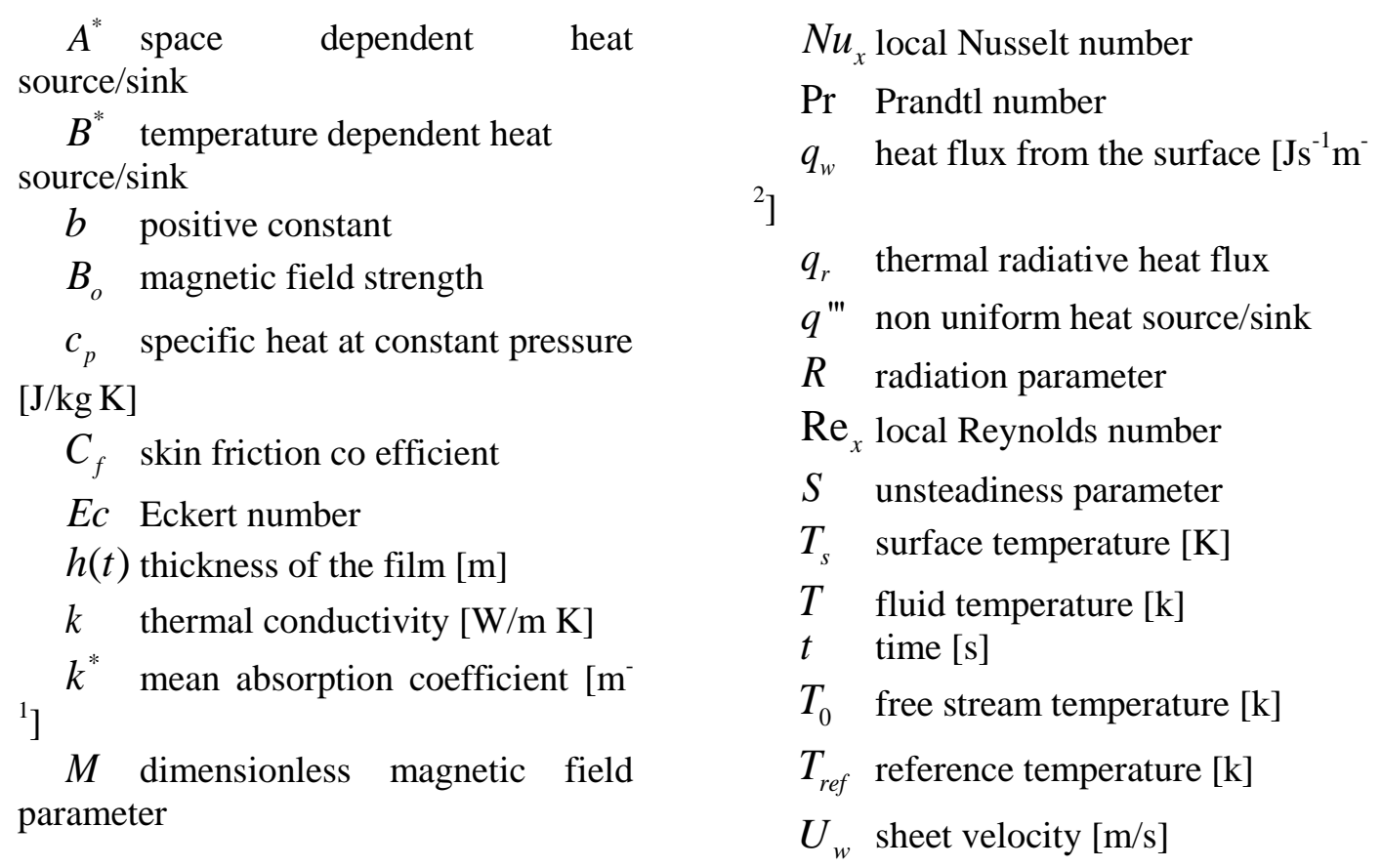


$u, v$ velocity components along the $\mathrm{x}$ and $\mathrm{y}$ - axes $[\mathrm{m} / \mathrm{s}]$

$x, y$ Cartesian coordinates [m]

$\tau_{w} \quad$ skin friction from the surface

$n$ power-law index parameter

Greek symbols

$v_{f} \quad$ kinematic viscosity of the fluid $\left[\mathrm{m}^{2} / \mathrm{s}\right]$

$\theta$ dimensionless temperature

$\sigma_{n f}$ electrical conductivity of the nanofluid $[\mathrm{S} / \mathrm{m}]$

$\left(\rho c_{p}\right)_{f} \quad$ heat capacity of the base fluid

$\left(\rho c_{p}\right)_{n f} \quad$ heat capacitance of the nanofluid $k_{n f} \quad \mu_{f} \quad$ dynamic viscosity of the base fluid

$\mu_{n f}$ dynamic viscosity of the nanofluid

$\rho_{n f}$ effective density of the nanofluid

$\psi$ stream function

$\sigma^{*} \quad \sigma \quad$ Stefan-Boltzmann constant

$\eta \quad$ similarity variable

\section{Subscripts}

$s \quad$ condition on the surface

$n f$ nanofluid

$f$ basefluid

p nanoparticle

\section{Introduction}

The study of momentum and heat transfer characteristics of boundary layer flow past a stretching sheet has gained considerable interest among the researchers because of its abundance of practical applications in various branches of engineering and industries, such as extrusion of plastics sheets, electronic cooling, nuclear reactors, cooling and drying of papers, metal spinning, glass fiber industries, wire drawing, hot rolling and many more. At this point it is worth to mention that, the final product of desired quality depends mainly on the rate of cooling and stretching rate in the process. Since Sakiadis [1] made the first attempt to analyse the flow behavior over a continuous solid surface moving with constant velocity. Later, the concept of two dimensional boundary layer flows over stretching sheet was initiated by Crane [2]. Further the problem of Crane [2] was extended by many investigators (Kumaran et al. [3], Hajmohammadi et at. [4] ) for various fluid flows over a stretching sheet. Recently, Raju et al. [5] reported a comparative study on heat and mass transfer in Jeffrey, Maxwell and Oldroyd-B nanofluids past a stretching surface by considering the thermophoresis, Brownian motion and magnetic field effects and found that heat and mass transfer rates are high in case of Oldroyd-B nanofluid when compared with other two nanofluids. On the other hand, the flow and heat transfer of a thin liquid film over an unsteady stretching sheet has received considerable attention of several researchers due to their enormous applications in several branches of science and technology such as heat exchangers, wire and fiber coating, chemical processing, transpiration cooling etc. Wang [6] initially studied the problem of thin film flow over an unsteady stretching sheet. Anderson et al. [7] extended Wang's problem by including heat transfer analysis in energy equation. Later, this problem was extended by Wang and Pop [8] and Nadeem and Awais [9] by considering the variable viscosity and power-law fluid. Abel et al. [10] discussed the magnetohydrodynamic flow and heat transfer analysis in a thin liquid film past an unsteady stretching sheet in presence of viscous dissipation. Bidyat and Dandapat [11] discussed the unsteady thin film flow over a heated stretching sheet. Recently, several researchers Abel et al. [12], Noor et al. [13], Nandeppanavar et al. [14], worked on the problem of thin film flow over a stretching sheet with various effects such as non-uniform heat source and thermal radiation. Very recently, Xang et al. [15] analysed the flow and heat transfer in a nano liquid film flow past an unsteady stretching sheet. Metri et al. [16] elaborated the effect of thermal radiation on the thin film flow and heat transfer of a fluid over a stretching sheet. 
Past few decades, the study of flow and heat transfer in nanofluids is an active research among the researchers because of its enhanced properties and tremendous applications in almost every field of science, technology and biomedicine viz. nuclear reactors, solar energy, cancer therapy, machining space technology etc. Initially, Choi [17] reported on enhancing the thermal conductivity of base fluid using the suspension of solid nano-meter sized particles into the base fluids commonly named as nanofluids. Further, a comprehensive study on enhancing the thermal conductivity of a fluid by using micro and nano meter scaled solid particles are found in book by Das et al. [18] and in research articles by Kakac and Pramuanja [19], Makinde and Aziz [20], Vajravelu et al. [21], Rana and Bhargava [22]. Later, Buongiorno [23] developed a model to enhance the thermal conductivity of base fluid and found that Brownian motion and thermophoresis effects are more prominent in nanofluids. Very recently, Sandeep and Sulochana [24] illustrated the flow and heat transfer behavior of dusty nanofluid past stretching sheet in the presence of suction/injection effects. Effect of thermal radiation on heat transfer analysis of a fluid past a stretching/shrinking sheet plays a vital role because of its numerous practical applications in the field of physics and engineering, such as polymer processing industry, solar power technology, gas turbines, astrophysical flows and many more. Several authors used Rosseland approximation to describe thermal radiation effect into the energy equation. Pal [25] studied the combined effects of radiation and non-uniform heat source/sink parameter on heat transfer characteristics of a fluid over an unsteady stretching sheet. Reddy et al. [25] analysed the heat transfer characteristics of unsteady magnetohydrodynamic flow of a fluid over stretching surface in the presence of viscous dissipation, thermal radiation and heat source parameters and they found that increase in the values of radiation, Eckert number and heat source parameter decreases the heat transfer rate near the surface. Recently, Thermal radiation effects on MHD nanofluid flow past a stretching surface in the presence of slip conditions was elaborated by Rizwan et al. [27].

Viscous dissipation affects the heat transfer rates proportionally by changing the temperature distributions and behaves as an energy source. Chen [28] discussed the effects of viscous dissipation and heat transfer characteristics of a non-Newtonian film flow past an unsteady stretching surface. Cortell [29] examined the viscous dissipation effects on flow and heat transfer of a viscous fluid over a nonlinear stretching sheet in the presence of thermal radiation. Later, Hunegnaw and Kishan [30] studied the problem of heat transfer over various geometries under the consideration of viscous dissipation effects. Further, Nandeppanavar et al. [31] illustrated viscous dissipation effect on viscoelastic fluid flow and heat transfer behaviour past a stretching sheet and found that the viscoelastic fluids having low viscous dissipation and more effective in cooling of stretching sheet.

In recent years, the study of flow and heat transfer of non-Newtonian fluids over a stretching/shrinking sheet has become a topic of active research among researchers because of its immense applications in science and technology, especially in biomedicine such as neurological treatment, food and polymer processing, in cancer treatment, blood flows, treatment of diagnostic diseases etc. shear stress and shear rate are indirectly proportional to non-Newtonian fluids. Carreau fluid is a type of Newtonian fluid. At high shear rate the Carreau fluid acts as power-law fluid and at low shear rate it behaves as Newtonian fluid. Carreau fluid model was developed by Carreau in 1972. Akbar et al. [32] numerically analysed the electrically conducting Carreau nanofluid flow in an asymmetric channel. Various studies are available on Carreau fluid flow analysis over different channels, few of them are, Raju and Sandeep [33], Sulochana et al. [34]. Recently, Massod et al. [35] studied the MHD flow of a non-Newtonian Carreau fluid over a heated surface.

All the above studies concentrated on analysing the heat transfer characteristics of thin film flows or other by considering the transverse magnetic field with one or more physical 
effects. Since, the external magnetic fields are very effective to set the thermal and physical properties of magnetic-nanofluids and regulate the flow and heat transfer characteristics, in this study; we investigate the flow and heat transfer characteristics of liquid thin film flow of $\mathrm{Fe}_{3} \mathrm{O}_{4}$-water and $\mathrm{CoFe}_{2} \mathrm{O}_{4}$-water nanofluids over a stretching sheet by considering the Carreau model in the presence of viscous dissipation, thermal radiation, variable heat source/sink and aligned magnetic field. Numerical computations are carried out and results are discussed with the help of graphs and tables.

\section{Mathematical Formulation}

Let us consider unsteady, two dimensional boundary layer flow of an electrically conducting and heat generating Carreau nanofluid over a stretching sheet bounded by a thin liquid film of uniform thickness $h(t)$ on a horizontal elastic sheet which emerges from a narrow slit at the origin of Cartesian coordinate system which is schematically represented in Fig.1. The sheet is stretched along the $x$-axis with stretching velocity $U(x, t)$ and $y$-axis is normal to it. An inclined magnetic field $B_{0}$ is applied to the stretching sheet at an angle $\gamma$. The effects of non-uniform heat source/sink, thermal radiation, viscous dissipation and volume fraction are taken into consideration.

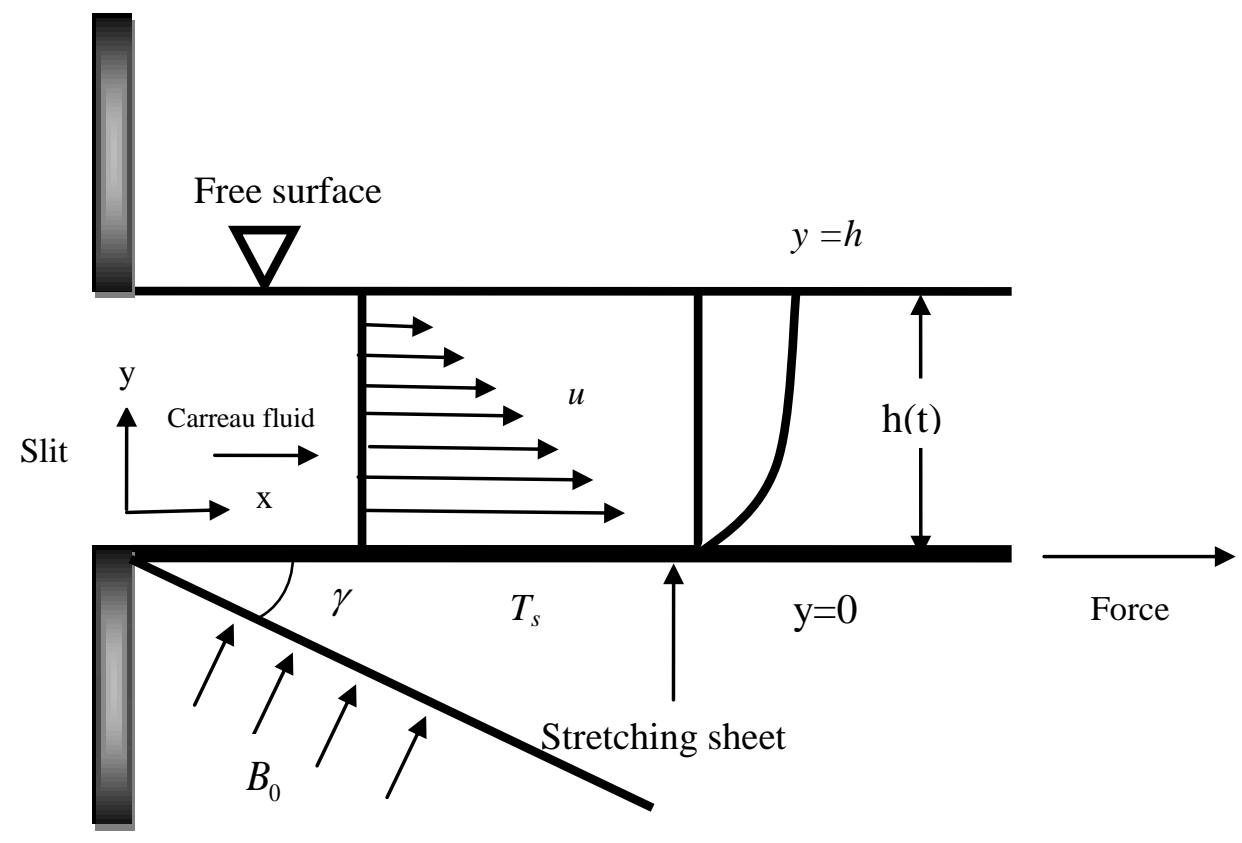

\section{Figure 1. Physical Model of the Problem}

We assume that the surface temperature $T_{s}$ of the stretching sheet varies with respect to distance $x$ from the slit as

$$
\begin{aligned}
& T_{s}=T_{0}-T_{r e f}\left(\frac{b x^{2}}{2 v_{f}}\right)(1-\alpha t)^{-\frac{3}{2}} \\
& U(x, t)=b x /(1-\alpha t)
\end{aligned}
$$

The Eqn. (2) is for the sheet velocity $U(x, t)$ reflects that the elastic sheet, the elastic sheet is fixed at the origin and stretched by applying a force in the positive $x$-direction. 
We used $\alpha>0$ because the stretching rate $b /(1-\alpha t)$ increases with time. Similarly, Eqn. (2) represents the decrease in sheet temperature from $T_{0}$ at the slit in proportion to $x^{2}$.

The constitutive equations for a Carreau fluid is given by

$$
\bar{\tau}_{i j}=\eta_{0}\left[1+\frac{(n-1)}{2}(\Gamma \overline{\dot{\gamma}})^{2}\right] \overline{\dot{\gamma}}_{i j}
$$

in which $\bar{\tau}_{i j}$ is the extra stress tensor, $\eta_{0}$ is the zero shear rate viscosity, $\Gamma$ is the time constant, $n$ is power-law index and $\overline{\dot{\gamma}}_{i j}$ is defined as

$$
\overline{\dot{\gamma}}=\sqrt{\frac{1}{2} \sum_{i} \sum_{j} \overline{\dot{\gamma}}_{i j} \overline{\dot{\gamma}}_{j i}}=\sqrt{\frac{1}{2}} \Pi \text {. }
$$

Here $\prod$ is the second invariant strain tensor.

The governing boundary layer equations for momentum and thermal energy with associated boundary conditions are

$$
\begin{gathered}
\frac{\partial u}{\partial x}+\frac{\partial v}{\partial y}=0 \\
\rho_{n f}\left(\frac{\partial u}{\partial t}+u \frac{\partial u}{\partial x}+v \frac{\partial u}{\partial y}\right)=\mu_{n f}\left(1+\frac{3(n-1) \Gamma^{2}}{2}\left(\frac{\partial u}{\partial y}\right)^{2}\right) \frac{\partial^{2} u}{\partial y^{2}}-\sigma B_{0}^{2} \cos ^{2} \gamma u \\
\left(\rho c_{p}\right)_{n f}\left(\frac{\partial T}{\partial t}+u \frac{\partial T}{\partial x}+v \frac{\partial T}{\partial y}\right)=k_{n f} \frac{\partial^{2} T}{\partial y^{2}}+\mu_{n f}\left(\frac{\partial u}{\partial y}\right)^{2}-\frac{\partial q_{r}}{\partial y}+q^{\prime \prime \prime} \\
\left.\begin{array}{c}
u=U_{w}, \quad v=0, \quad T=T_{s} \text { at } \mathrm{y}=0, \\
\text { (7) } \frac{\partial u}{\partial y}=0, \quad \frac{\partial T}{\partial y}=0, \text { at } \mathrm{y}=\mathrm{h}, \\
v=\frac{d h}{d t} \text { as } y=h(t),
\end{array}\right\},
\end{gathered}
$$

where

$$
\left.\begin{array}{l}
\rho_{n f}=(1-\phi) \rho_{f}+\phi \rho_{s}, \quad \mu_{n f}=\frac{\mu_{f}}{(1-\phi)^{2.5}}, k_{n f}=k_{f}\left[\frac{k_{s}+2 k_{f}-2 \phi\left(k_{f}-k_{s}\right)}{k_{s}+2 k_{f}+\phi\left(k_{f}-k_{s}\right)}\right] \\
\left(\rho c_{p}\right)_{n f}=(1-\phi)\left(\rho c_{p}\right)_{f}+\phi\left(\rho c_{p}\right)_{s}
\end{array}\right\},
$$

(9) Using Rosseland approximation of radiation we get

$$
q_{r}=-\frac{4 \sigma^{*}}{3 k^{*}} \frac{\partial T^{4}}{\partial y}
$$

Now by expanding $T^{4}$ is a linear temperature function which is expanded by using Taylor series expansion about $T_{0}$ as

$$
T^{4}=4 T_{0}^{3} T-3 T_{0}^{4},
$$

Using (10)-(11) in equation (7) we get

$$
\left(\rho c_{p}\right)_{n f}\left(\frac{\partial T}{\partial t}+u \frac{\partial T}{\partial x}+v \frac{\partial T}{\partial y}\right)=k_{n f} \frac{\partial^{2} T}{\partial y^{2}}+\mu_{n f}\left(\frac{\partial u}{\partial y}\right)^{2}+\frac{16 \sigma^{*} T_{0}^{3}}{3 k^{*}} \frac{\partial^{2} T}{\partial y^{2}}+q^{\prime \prime \prime},
$$

The non uniform heat generation/absorption $q$ "' has taken as 


$$
q^{\prime \prime}=\frac{k_{f} U_{w}}{x v_{f}}\left[A^{*}\left(T_{s}-T_{0}\right) f^{\prime}+B^{*}\left(T-T_{0}\right)\right],
$$

Let us now introduce the similarity variables as given below

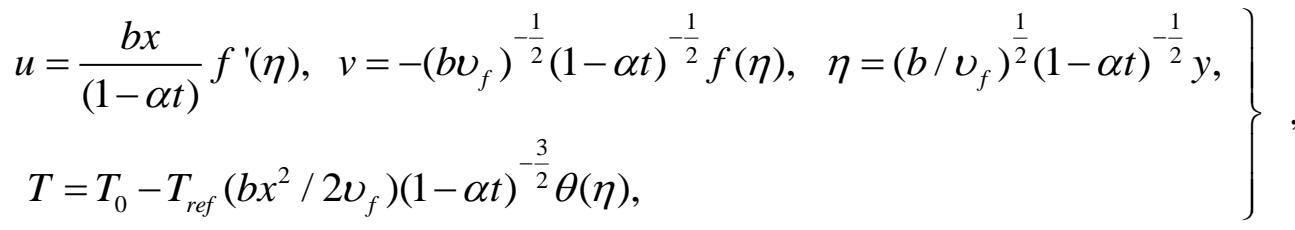

Now by using the similarity variables the equations (6) and (12) reduces to the nondimensional form with associated boundary conditions as

$$
\begin{aligned}
& f^{\prime \prime \prime}\left(1+\frac{3(n-1)}{2} W_{e} f^{\prime \prime 2}\right)+B_{1}\left\{B_{2}\left(S\left(f^{\prime}+\frac{\eta}{2} f^{\prime \prime}\right)+f f^{\prime \prime}-f^{\prime 2}\right)-M \cos ^{2} \gamma f^{\prime}\right\}=0, \\
& \left(B_{3}+\frac{4}{3} R\right) \theta^{\prime \prime}+\frac{E c \operatorname{Pr}}{B_{1}} f^{\prime \prime 2}+\left(A^{*} f^{\prime}+B^{*} \theta\right)-B_{4} \operatorname{Pr}\left(\frac{S}{2}\left(\eta \theta^{\prime}+3 \theta\right)+2 f^{\prime} \theta-f \theta^{\prime}\right)=0,
\end{aligned}
$$

where,

$$
B_{1}=(1-\phi)^{2.5}, \quad B_{2}=1-\phi+\phi \frac{\rho_{s}}{\rho_{f}}, B_{3}=\frac{k_{n f}}{k_{f}}, B_{4}=1-\phi+\phi \frac{\left(\rho c_{p}\right)_{s}}{\left(\rho c_{p}\right)_{f}},
$$

Corresponding boundary conditions are

$$
\left.\begin{array}{l}
f^{\prime}(0)=1, \quad f(0)=0, \quad \theta(0)=0, \\
f^{\prime \prime}(\beta)=0, \quad \theta^{\prime}(\beta)=0, \quad f(\beta)=\frac{S \beta}{2}
\end{array}\right\},
$$

here $S=\alpha / b$ is unsteadiness parameter and prime represents differentiation with respect to $\eta$. Further, $\beta$ indicates the value of the similarity variable $\eta$ at the free surface so that $\eta$ value gives

$$
\beta=\left(\frac{b}{v_{f}(1-\alpha t)}\right)^{\frac{1}{2}} h,
$$

The rate at which film thickness varies can be obtained by differentiating (19) w.r.t. t,

$$
\frac{d h}{d t}=-\frac{\alpha \beta}{2}\left(\frac{v_{f}}{b(1-\alpha t)}\right)^{\frac{1}{2}},
$$

where,

$$
\operatorname{Pr}=\left(\mu c_{p}\right)_{f} / k_{f}, \quad W e^{2}=\frac{b^{3} x^{2} \Gamma^{2}}{v_{f}(1-\alpha t)^{3}}, \quad M=\frac{\sigma B_{0}^{2}}{\rho_{f} b}, \quad R=\frac{4 \sigma^{*} T_{0}^{3}}{k^{*} k_{f}}, \quad S=\frac{\alpha}{b}, \quad E c=\frac{U_{w}^{2}}{c_{p}\left(T_{s}-T_{0}\right)},
$$

The physical quantities of practical interest in this problem are the skin friction coefficient $C_{f}$ and the Nusselt number $N u$, which are given as

$$
\begin{aligned}
& C_{f}=\frac{\tau_{w}}{\rho_{f} U_{w}^{2}}, \quad N u=\frac{q_{w} x}{k_{f}\left(T_{s}-T_{0}\right)}, \\
& \text { where, } \quad \tau_{w}=\mu_{n f}\left(\frac{\partial u}{\partial y}\right)_{y=0}, \quad q_{w}=-K_{n f}\left(\frac{\partial T}{\partial y}\right)_{y=0},
\end{aligned}
$$

Substituting Eqn. (22) in Eqn. (23), we obtain 


$$
B_{1} C_{f x} \operatorname{Re}_{x}^{-1 / 2}=f^{\prime \prime}(0), \quad\left(1 / B_{3}\right) N u_{x} \operatorname{Re}_{x}^{1 / 2}=-\theta^{\prime}(0),
$$

where, $\operatorname{Re}_{x}=U_{w} x / v_{f}$ is the local Reynolds number.

\section{Result Discussion}

To study the problem more effectively the system of coupled ordinary differential equations with respect to the boundary conditions are solved numerically using RungeKutta based shooting technique. We considered two special types of nanoparticles namely $\mathrm{Fe}_{3} \mathrm{O}_{4}$ and $\mathrm{CoFe}_{2} \mathrm{O}_{4}$ and water is considered as the base fluid. The results obtained shows the influence of non-dimensional parameters such as, aligned angle $\gamma$, magnetic field parameter $M$, volume fraction of the nanoparticles $\phi$, unsteadiness parameter $S$, thermal radiation parameter $R$, non-uniform heat source/sink parameters $A^{*}$ and $B^{*}$, viscous dissipation parameter $E c$, Weissenberg number $W e$, power-law index parameter $n$ and the boundary layer thickness parameter $\beta$ on velocity and temperature profiles of the flow along with friction factor and local Nusselt number. For numerical calculations we considered $S=0.5 ; A^{*}=0.2 ; B^{*}=0.2 ; M=2 ; W e=0.5 ; n=1.5 ; E c=0.1 ; \gamma=\pi / 4 ; R=1$.

And these values are treating as common in the entire study except the varied values are displayed in the respective figure and tables.

Figs. 2 and 3 portray the effect of aligned magnetic field on velocity and temperature profiles of the flow for $\mathrm{Fe}_{3} \mathrm{O}_{4}$-water and $\mathrm{CoFe}_{2} \mathrm{O}_{4}$-water nanofluids. We observed a rise in velocity and depreciation in temperature fields for increasing values of aligned angle. Generally, rise in the aligned angle weaken the applied magnetic field strength, this causes to decline the drag forces acting opposite to the flow direction. We have noticed opposite results to above for increasing values of magnetic field parameter, which are displayed in Figs. 4 and 5. Physically, increasing values of magnetic field develops a resistive type of force known as Lorentz force. Due to this force we observed declination in the velocity profiles and hike in temperature profiles of the flow.

Fig.6 and 7 presented to study the effect of unsteadiness parameter $S$ on velocity and temperature profiles. We observed that an enhancement in velocity profiles and depreciation in temperature profiles for increasing values of $S$. Physically, increasing the unsteadiness causes to fluctuate the buoyancy forces acts on the flow field. Due to this reason we have seen a rise in the velocity filed. It is interesting to mention that temperature field of $\mathrm{CoFe}_{2} \mathrm{O}_{4}$-water nanofluid is highly influenced by unsteadiness parameter when compared with $\mathrm{Fe}_{3} \mathrm{O}_{4}$-water nanofluid.

Fig. 8 and 9 describes the effect of Weissenberg number We on velocity and temperature profiles of the flow. It is obvious that an increase in Weissenberg number depreciates the velocity and enhances temperature profiles of the flow. Physically, $W e$ is proportional to the ratio of time constant to viscosity and this ratio is larger for increasing values of $W e$, as a result we have seen a hike in velocity and temperature profiles. We have noticed a gradual decrement in temperature profiles of $\mathrm{CoFe}_{2} \mathrm{O}_{4}$-water nanofluid for rising values of Weissenberg number.

Fig. 10 and 11 reveals the effect of power-law index parameter $n$ on velocity and temperature fields of the flow. It is clear that increasing values of power-law index parameter enhances the velocity profiles and declines the temperature profiles of the flow. Generally, hike in power-law index enhances the nonlinearity of the sheet as a result the resistive force will minimise. Hence we observed a rise in momentum boundary layer and depreciation in thermal boundary layer.

Fig. 12 and 13 depicts the influence of non-uniform heat source/sink parameters $A^{*}$ and $B^{*}$ on temperature profiles of the flow. It is evident that increasing values of non-uniform heat source/sink parameter enhances the temperature profiles of the flow. Physically, 
positive values $A^{*}$ and $B^{*}$ behaves as heat generators and negative values of $A^{*}$ and $B^{*}$ behaves as heat absorbers. Due to this reason we observed the enhancement in temperature profiles for positive values of $A^{*}$ and $B^{*}$. Fig. 14 displays the effect of thermal radiation parameter $R$ on temperature profiles of the flow. It is clear that rising values of radiation parameter enhances the temperature profiles of the flow. This may happens due to the fact that increase in radiation supplies the heat energy to the flow, as a result fluid temperature increases and thermal boundary layer thickens.

Fig. 15 shows the effect of viscous dissipation parameter $E c$ on temperature profiles of the flow. It is noticed that increasing values of viscous dissipation parameter enhances the temperature profiles of the flow. Generally, rise in the viscous dissipation improves the thermal conductivity of the fluid. Due to this reason we observed an enhancement in temperature profiles of the flow. Fig. 16 and 17 displays the velocity and temperature profiles for various values of volume fraction parameter $\phi$. It is evident that increasing values of $\phi$ enhances the velocity and temperature profiles of the flow. We observe a significant change in the velocity profiles of $\mathrm{CoFe}_{2} \mathrm{O}_{4}$-water and $\mathrm{Fe}_{3} \mathrm{O}_{4}$-water nanofluids for increasing values of $\phi$. Fig. 18 and 19 depicts the effect of boundary layer thickness parameter $\beta$ on velocity and temperature profiles of the flow. It is observed that an increase in $\beta$ depreciate the velocity and temperature profiles of the flow. Physically, rise in the value of $\beta$ enlarges the thickness of momentum and thermal boundary layers. Due to this reason we noticed depreciation in velocity and temperature fields.

Table 1 displays the thermophysical properties of water and nanoparticles. Table 2 and 3 portrays the effect of various non-dimensional governing parameters on skin friction coefficient and local Nusselt number for $\mathrm{Fe}_{3} \mathrm{O}_{4}$-water and $\mathrm{CoFe}_{2} \mathrm{O}_{4}$-water nanofluids. It is evident that volume fraction of nanoparticles reduces the heat transfer rate. Weissenberg number $W e$, unsteadiness parameter $S$, inclined angle $\gamma$ and boundary layer thickness parameter $\beta$ enhances both local skin friction and Heat transfer rate in both the solutions.

Thermal radiation $R$, non-uniform heat source/sink parameter $A^{*}$ and $B^{*}$ shows no effect on local skin friction, but it reduces the heat transfer rates. The nanoparticle volume fraction $\phi$ enhances the skin friction but decreases the local Nusselt number for both the solutions. Table 4 depicts the comparison of the present results with the published results. We found a good agreement of the present results with the published results under some special and limited cases. This proves that present results are valid.

\section{Table 1. Thermo Physical Properties of the Nano and Ferro Particles with Base Fluid}

(Oztop et al. [36])

\begin{tabular}{|c|c|c|c|}
\hline $\begin{array}{c}\text { Physical } \\
\text { properties }\end{array}$ & $\begin{array}{c}\text { Fluid phase } \\
\text { (water) }\end{array}$ & $\mathrm{Fe}_{3} \mathrm{O}_{4}$ & $\mathrm{CoFe}_{2} \mathrm{O}_{4}$ \\
\hline$c_{p}(\mathrm{~J} / \mathrm{KgK})$ & 4179 & 670 & 700 \\
\hline$\rho\left(\mathrm{Kg} / \mathrm{m}^{3}\right)$ & 997.1 & 5180 & 4907 \\
\hline$k(\mathrm{~W} / \mathrm{mK})$ & 0.613 & 9.7 & 3.7 \\
\hline
\end{tabular}


Table 2. Physical Parameter Values of $f^{\prime \prime}(0)$ and $-\theta^{\prime}(0)$ for $\mathbf{F e}_{3} \mathbf{O}_{4}$-water Nanofluid.

\begin{tabular}{|l|l|l|l|l|l|l|l|l|l|l|l|l|}
\hline$\phi$ & $M$ & $S$ & $W e$ & $n$ & $A^{*}$ & $B^{*}$ & $R$ & $E c$ & $\gamma$ & $\beta$ & \multicolumn{2}{|c|}{$\mathrm{Fe}_{3} \mathrm{O}_{4}$-water } \\
\hline 0.1 & & & & & & & & & & & -0.666500 & 2.370731 \\
\hline 0.2 & & & & & & & & & & & -0.606030 & 2.203418 \\
\hline 0.3 & & & & & & & & & & & -0.521501 & 2.039473 \\
\hline & 1 & & & & & & & & & & -0.666500 & 2.370731 \\
\hline & 2 & & & & & & & & & & -0.833150 & 2.327607 \\
\hline & 3 & & & & & & & & & & -0.970603 & 2.290111 \\
\hline & & 0.2 & & & & & & & & & -0.806974 & 2.251767 \\
\hline & & 0.4 & & & & & & & & & -0.717264 & 2.335355 \\
\hline & & & & & & & & & & & -0.611307 & 2.402829 \\
\hline & & & 3 & & & & & & & & -0.480693 & 2.404085 \\
\hline & & 5 & & & & & & & & -0.390056 & 2.423802 \\
\hline & & & & 1 & & & & & & & -0.682297 & 2.368350 \\
\hline & & & & 5 & & & & & & & -0.594688 & 2.382184 \\
\hline & & & & 10 & & & & & & & -0.538387 & 2.392512 \\
\hline & & & & & 1 & & & & & & -0.666500 & 2.255124 \\
\hline & & & & & 2 & & & & & & -0.666500 & 2.110615 \\
\hline & & & & & 3 & & & & & & -0.666500 & 1.966106 \\
\hline & & & & & & 1 & & & & & -0.666555 & 2.297984 \\
\hline & & & & & 2 & & & & & -0.666555 & 2.203243 \\
\hline & & & & & & 3 & & & & & -0.666555 & 2.103432 \\
\hline & & & & & & & 1 & & & & -0.666500 & 2.370731 \\
\hline & & & & & & 2 & & & & -0.666500 & 1.962488 \\
\hline & & & & & & & 3 & & & & -0.666500 & 1.688719 \\
\hline & & & & & & & & 1 & & & -0.666555 & 2.152623 \\
\hline & & & & & & & & 2 & & & -0.666555 & 1.910412 \\
\hline & & & & & & & 3 & & & -0.666555 & 1.668200 \\
\hline & & & & & & & & & $\pi / 4$ & & -0.833150 & 2.327607 \\
\hline & & & & & & & & & $\pi / 3$ & & -0.666500 & 2.370731 \\
\hline & & & & & & & & & & 1.5 & -0.935977 & 2.329247 \\
\hline
\end{tabular}

Table 3. Physical Parameter Values of $f^{\prime \prime}(0)$ and $-\theta^{\prime}(0)$ for $\mathrm{CoFe}_{2} \mathrm{O}_{4}$-water Nanofluid.

\begin{tabular}{|c|c|c|c|c|c|c|c|c|c|c|c|c|}
\hline$\phi$ & $M$ & $S$ & $W e$ & $n$ & $A^{*}$ & $B^{*}$ & $R$ & $E c$ & $\gamma$ & $\beta$ & \multicolumn{2}{|c|}{$\mathrm{CoFe}_{2} \mathrm{O}_{4}$-water } \\
\hline 0.1 & & & & & & & & & & & -0.660332 & 2.408800 \\
\hline 0.2 & & & & & & & & & & & -0.596309 & 2.279990 \\
\hline 0.3 & & & & & & & & & & & -0.510401 & 2.155543 \\
\hline & 1 & & & & & & & & & & -0.660332 & 2.408800 \\
\hline & 2 & & & & & & & & & & -0.827771 & 2.365280 \\
\hline & 3 & & & & & & & & & & -0.965764 & 2.327408 \\
\hline
\end{tabular}




\begin{tabular}{|c|c|c|c|c|c|c|c|c|c|c|c|c|}
\hline & & 0.2 & & & & & & & & & -0.799113 & 2.294342 \\
\hline & & 0.4 & & & & & & & & & -0.710420 & 2.374789 \\
\hline & & 0.6 & & & & & & & & & -0.605864 & 2.439775 \\
\hline & & & 1 & & & & & & & & -0.624425 & 2.414312 \\
\hline & & & 3 & & & & & & & & -0.477628 & 2.441852 \\
\hline & & & 5 & & & & & & & & -0.387868 & 2.461439 \\
\hline & & & & 1 & & & & & & & -0.675702 & 2.406461 \\
\hline & & & & 5 & & & & & & & -0.590034 & 2.420128 \\
\hline & & & & 10 & & & & & & & -0.534607 & 2.430365 \\
\hline & & & & & 1 & & & & & & -0.660332 & 2.291149 \\
\hline & & & & & 2 & & & & & & -0.660332 & 2.144087 \\
\hline & & & & & 3 & & & & & & -0.660332 & 1.997023 \\
\hline & & & & & & 1 & & & & & -0.660332 & 2.335402 \\
\hline & & & & & & 2 & & & & & -0.660381 & 2.239563 \\
\hline & & & & & & 3 & & & & & -0.660381 & 2.138765 \\
\hline & & & & & & & 1 & & & & -0.660332 & 2.408800 \\
\hline & & & & & & & 2 & & & & -0.660332 & 1.986482 \\
\hline & & & & & & & 3 & & & & -0.660332 & 1.705787 \\
\hline & & & & & & & & 1 & & & -0.660381 & 2.189150 \\
\hline & & & & & & & & 2 & & & -0.660381 & 1.945214 \\
\hline & & & & & & & & 3 & & & -0.660381 & 1.701279 \\
\hline & & & & & & & & & $\pi / 6$ & & -0.965764 & 2.327408 \\
\hline & & & & & & & & & $\pi / 4$ & & -0.827771 & 2.365281 \\
\hline & & & & & & & & & $\pi / 3$ & & -0.660332 & 2.408800 \\
\hline & & & & & & & & & & 0.5 & -0.565384 & 2.114083 \\
\hline & & & & & & & & & & 1.0 & -0.827771 & 2.365281 \\
\hline & & & & & & & & & & 1.5 & -0.930492 & 2.364583 \\
\hline
\end{tabular}

Table 4. Comparison of Values $-\theta^{\prime}(0)$ for Different Values of $S$ when

$$
R=M=E c=0 \text { and } \operatorname{Pr}=1 \text {. }
$$

\begin{tabular}{|c|c|c|}
\hline & \multicolumn{2}{|c|}{$\phi=0$} \\
\hline$S$ & Xu et al. [37] & Present Results \\
\hline 1.0 & 2.677222162 & 2.6772221621 \\
\hline 1.2 & 1.999591426 & 1.9995914260 \\
\hline 1.4 & 1.447754361 & 1.4477543611 \\
\hline 1.6 & 0.956697844 & 0.9566978443 \\
\hline
\end{tabular}




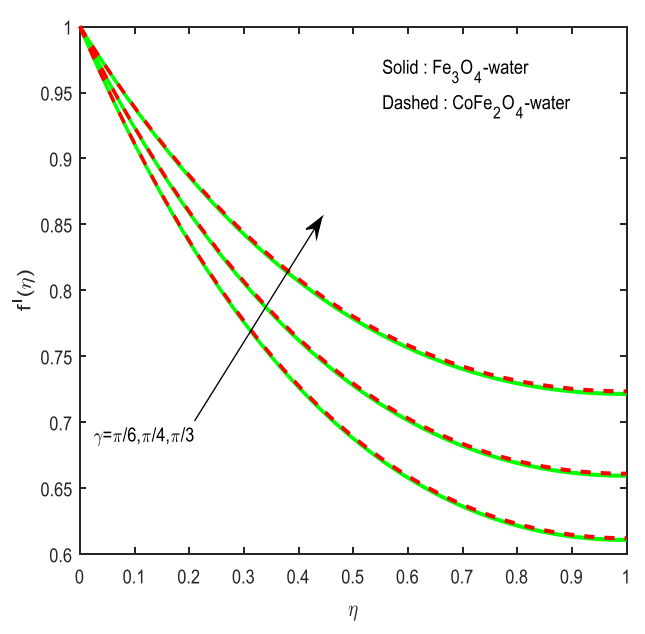

Figure 2. Velocity Fields for Various Values of $\gamma$

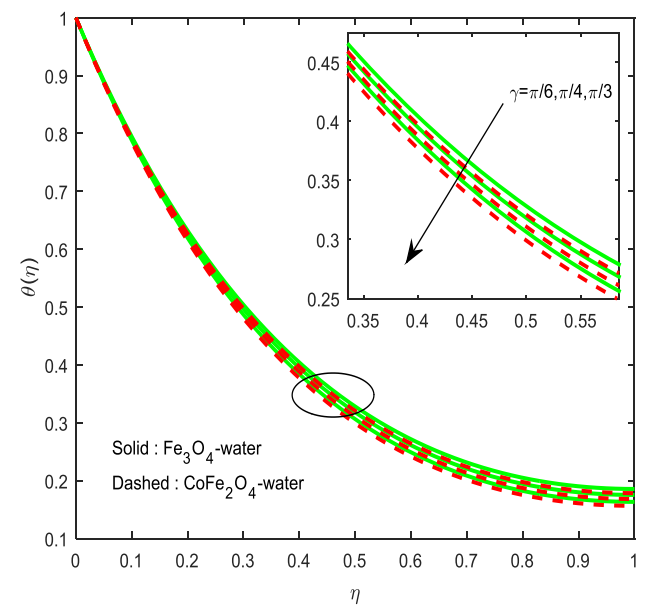

Figure 3. Temperature Fields for Various Values of $\gamma$

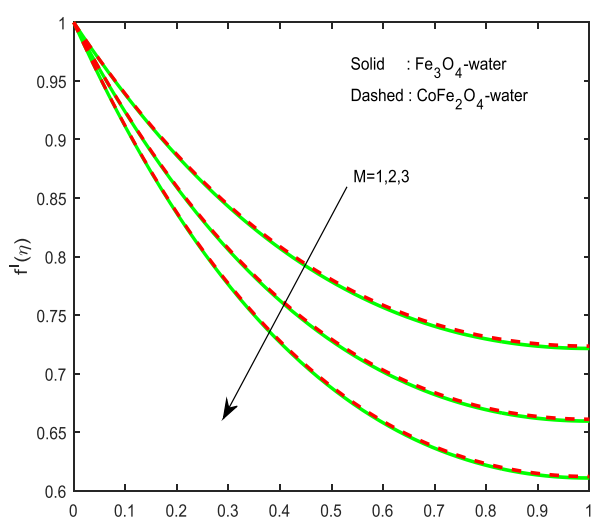

Figure 4. Velocity Fields for Various Values of $M$

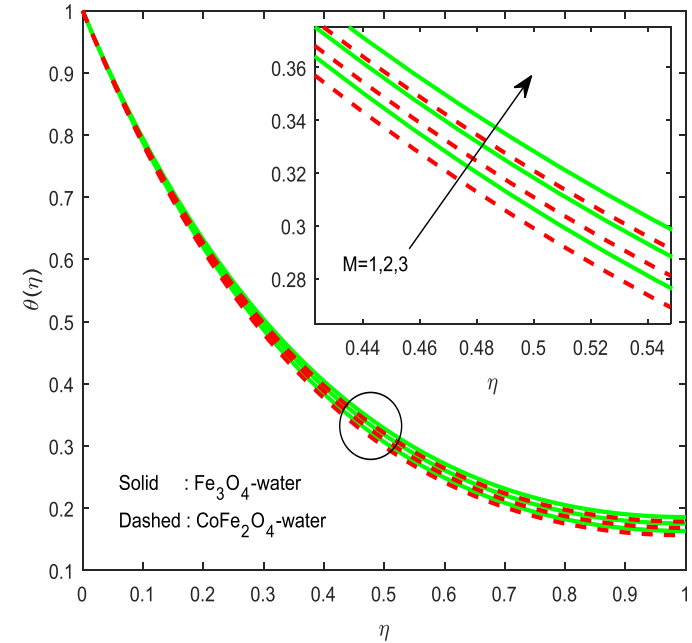

Figure 5. Temperature Fields for Various Values of $M$

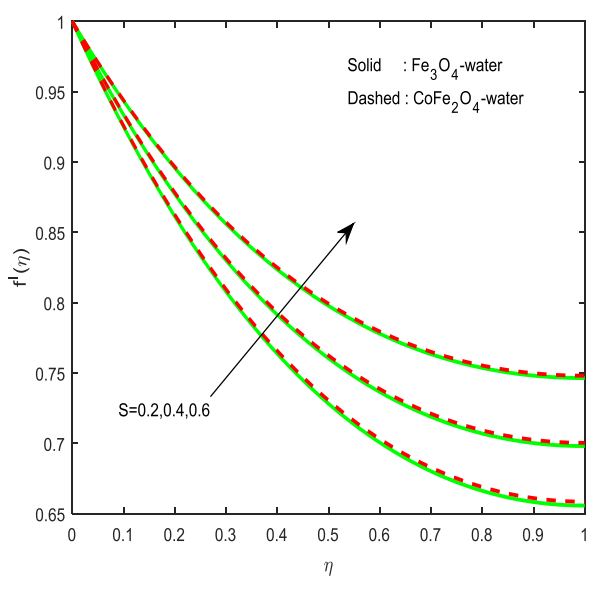

Figure 6. Velocity Fields for Various Values of $S$

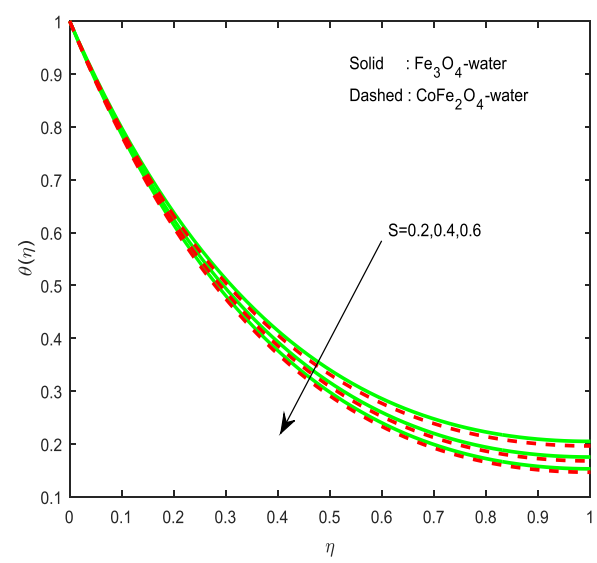

Figure 7. Temperature Fields for Various Values of $S$ 


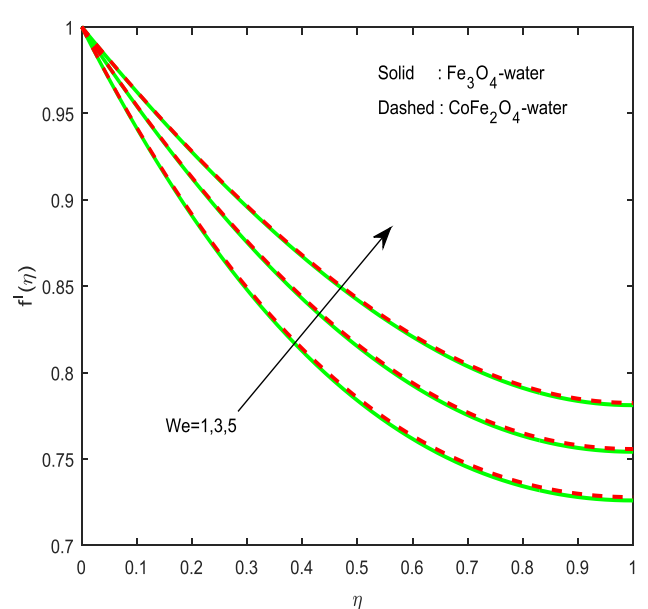

Figure 8. Velocity Fields for

Various Values of $W e$

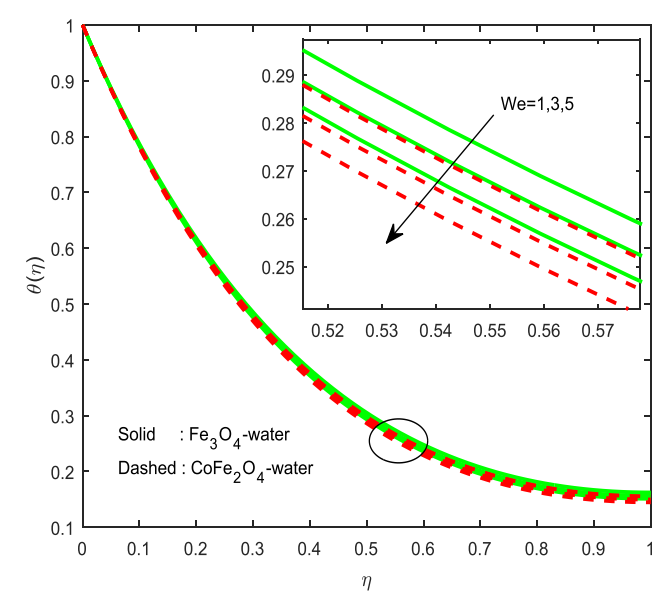

Figure 9. Temperature Fields for Various Values of $W e$

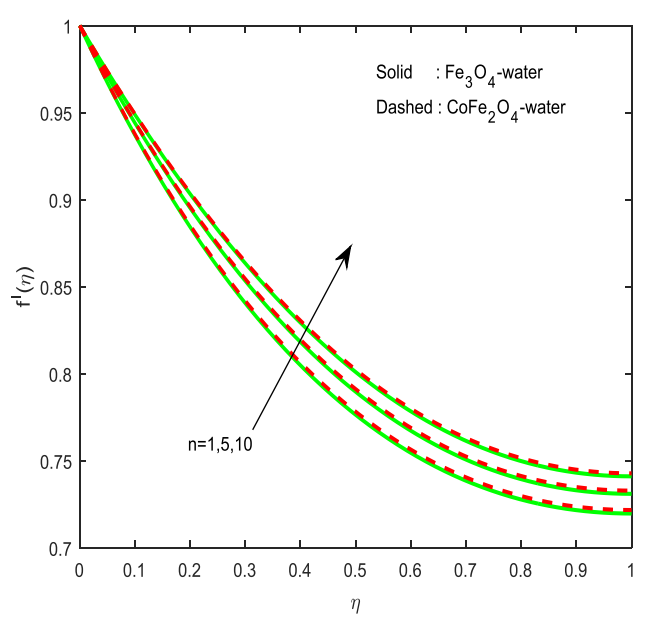

Figure 10. Velocity Fields for Various Values of $n$

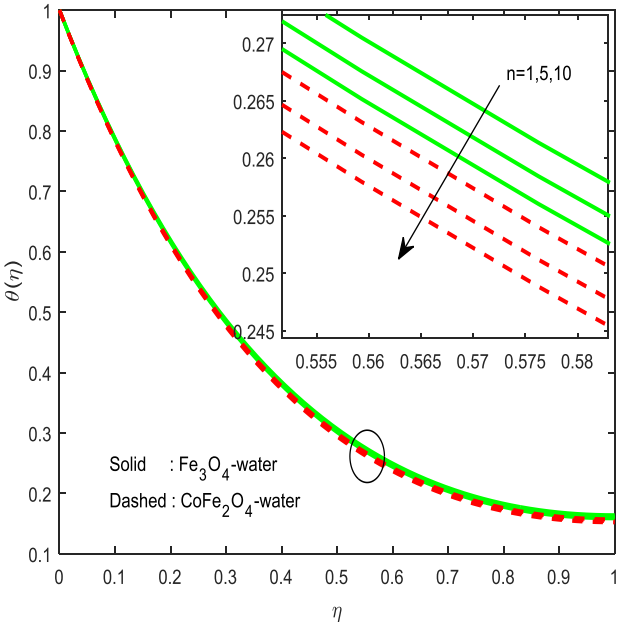

Figure 11. Temperature Fields for Various Values of $n$

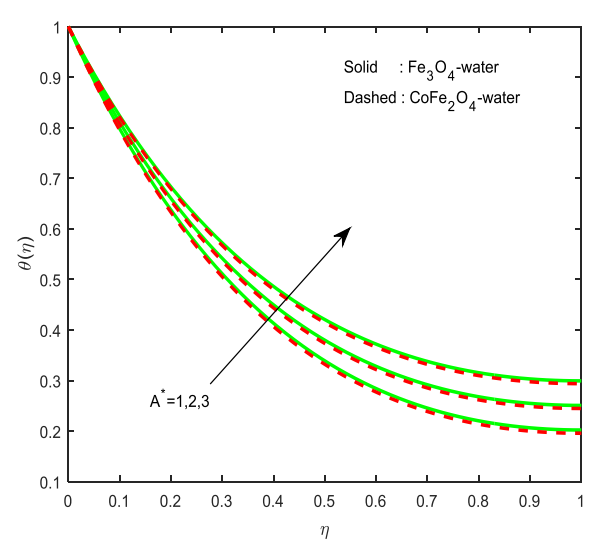

Figure 12. Temperature Fields for Various Values of $A^{*}$

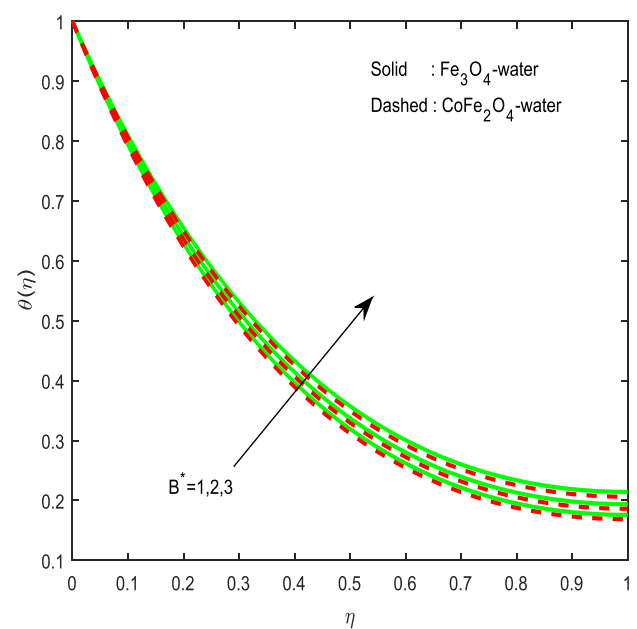

Figure 13. Temperature Fields for Various Values of $B^{*}$ 


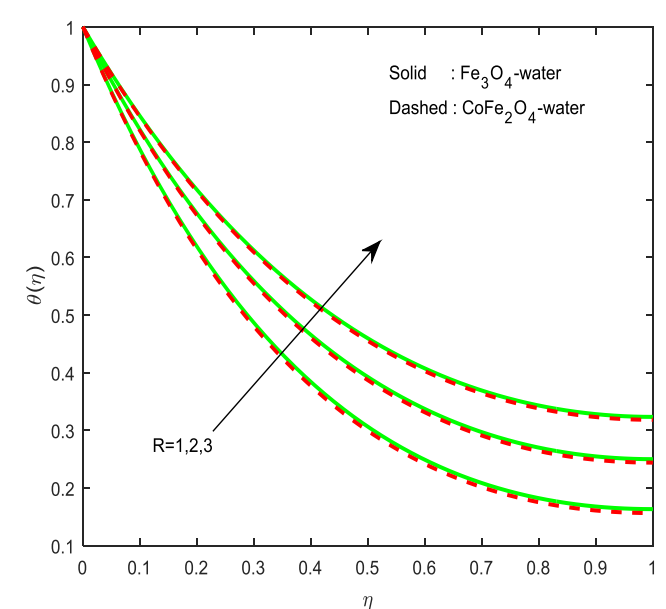

Figure 14. Temperature Fields for Various Values of $R$

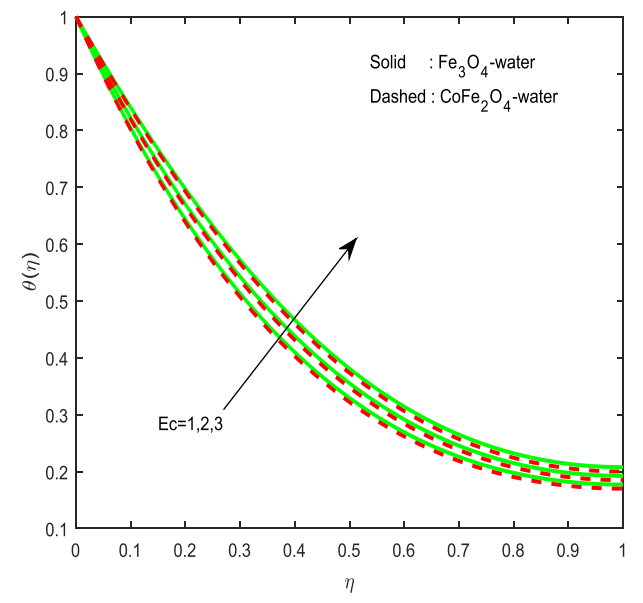

Figure 15. Temperature Fields for Various Values of $E c$

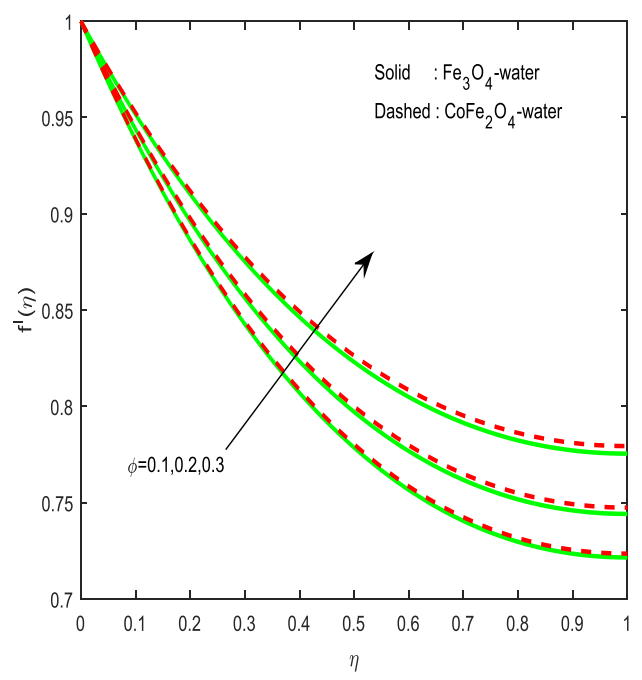

Figure 16. Velocity Fields for Various Values of $\phi$

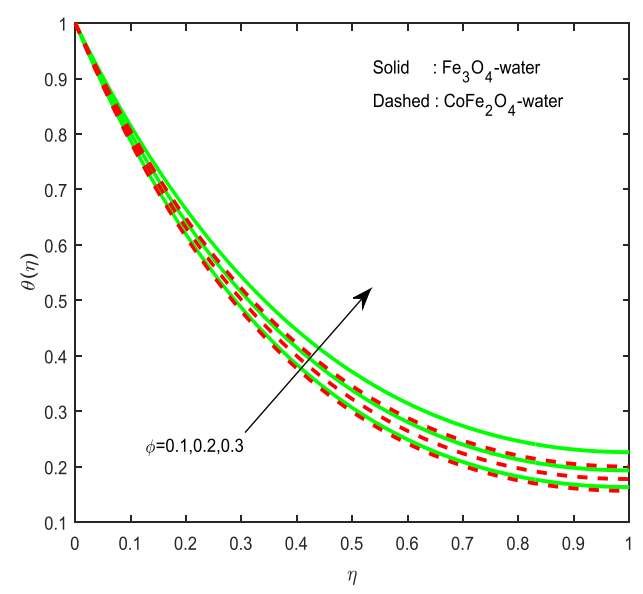

Figure 17. Temperature Fields for Various Values of $\phi$

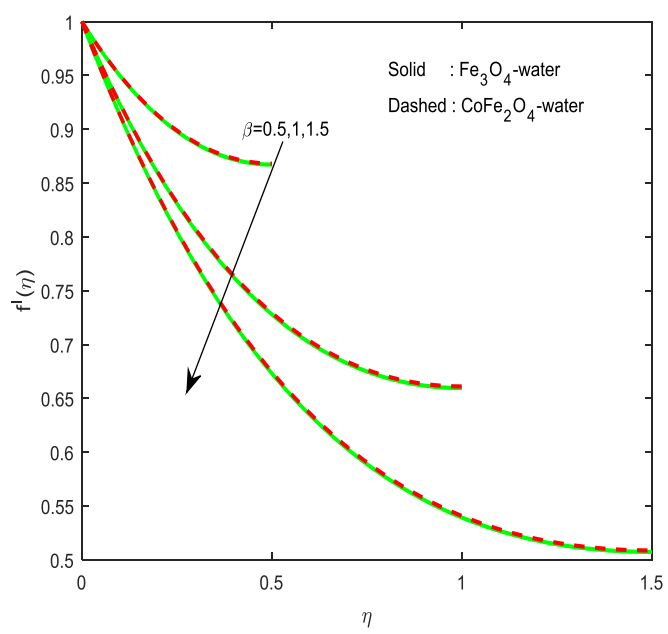

Figure 18. Velocity Fields for Various Values of $\beta$

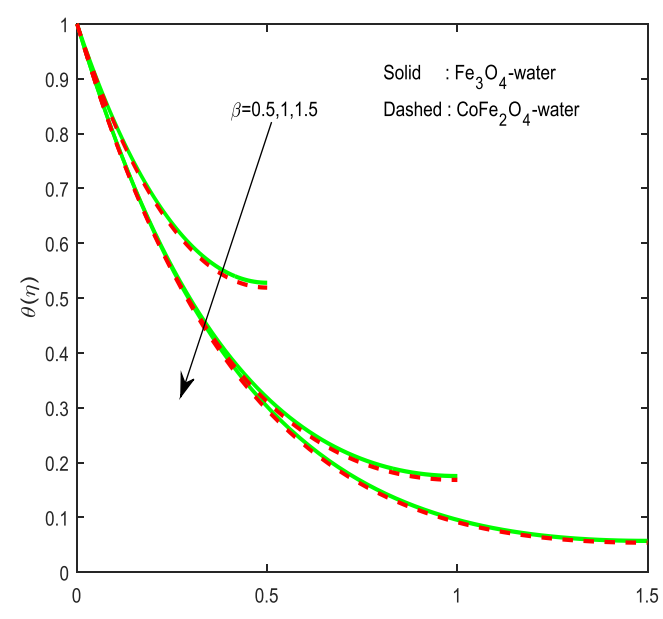

Figure 19. Temperature Fields for Various Values of $\beta$ 


\section{Conclusion}

Due to the numerous importance of magnetic field to set the thermal and physical properties of magnetic-nanofluids and regulate the flow and heat transfer characteristics, in this study; we investigated the flow and heat transfer characteristics of liquid thin film flow of $\mathrm{Fe}_{3} \mathrm{O}_{4}$-water and $\mathrm{CoFe}_{2} \mathrm{O}_{4}$-water nanofluids over a stretching sheet by considering the Carreau model in the presence of viscous dissipation, thermal radiation, variable heat source/sink and aligned magnetic field. The conclusions are made as follows.

- Unsteadiness parameter have tendency to enhance both the skin friction and heat transfer rate.

- $\quad$ Rising values of Weissenberg number and Power- law index parameter shows the effective enhancement in heat transfer rate.

- $\quad$ Aligned magnetic field angle regulates the flow and heat transfer

- $\quad$ Rising the boundary layer thickness enhances the heat transfer rate.

- Non-uniform heat source/sink parameters controls the thermal boundary layer thickness.

- Heat transfer rate is high in $\mathrm{CoFe}_{2} \mathrm{O}_{4}$-water nanofluid when compared with $\mathrm{Fe}_{3} \mathrm{O}_{4}$ -water nanofluid.

\section{Acknowledgement}

First author acknowledge the UGC SAP DRS-III for facilitating this work.

\section{References}

[1] BC. Sakiadis, "Boundary layer behavior on continuous solid surfaces:II", The boundary layer on a continuous flat surface, AIChE J, (1961) vol. 7, no. 2, 221-225.

[2] LJ. Crane, "Flow past a stretching plate", Z. Angew. Math. phys., 21, (1970), pp. 645-647.

[3] V. Kumaran, AK. Banerjee, A. Vanav Kumar and I. Pop, "Unsteady MHD flow and heat transfer with viscous dissipation past a stretching sheet", Int. Comm. Heat and Mass Transfer, vol. 38, (2011), 335339.

[4] M.R. Hajmohammadi, H. Maleki, G. Lorenzini and S.S. Nourazar, "Effects of $\mathrm{Cu}$ and Ag nano particles on flow and heat transfer permeable surfaces", Advanced Powder Technology, vol. 26, no. 1, (2015), 193-199.

[5] N. Sandeep, B. Rushi Kumar and M.S. Jagadeesh Kumar, "A comparative study of convective heat and mass transfer in non-Newtonian nanofluid flow past a permeable stretching sheet", J. Molecular Liquids, vol. 212, (2015), pp. 585-591.

[6] C.Y. Wang, "Liquid film on an unsteady stretching surface", Quarterly of applied Mathematics, vol. 48, (1990), pp. 601-610.

[7] H.I. Andersson, J.B. Aarseth and B.S. Dandapat, "Heat transfer in a liquid film on an unsteady stretching surface”, Int. J. Heat Mass Transfer, vol. 43, (2000), pp. 69-74.

[8] C. Wang and I. Pop, "Analysis of the flow of a power -law fluid film on an unsteady stretching surface by means of homotopy analysis method", J. Non-Newtonian Fluid Mech, vol. 138, (2006), pp. 161-172.

[9] S. Nadeem and M. Awais, "Thin film flow of an unsteady shrinking sheet through porous medium with variable viscosity", Physics letters A, vol. 372, (2008), pp. 4965-4972.

[10] M.S. Abel, N. Mahesha and J. Tawade, "Heat transfer in a liquid film over an unsteady stretching surface with viscous dissipation in presence of external magnetic field", Applied Mathematical Modelling, vol. 33, no. 8, (2009), pp. 3430-3441.

[11] B. Santra and B.S. Dandapat, "Unsteady thin-film flow over a heated stretching sheet", International Journal of Heat and Mass Transfer, vol. 52, no. 7-8, (2009), pp. 1965-1970.

[12] M.S. Abel, J. Tawade and M.M. Nandeppanavar, "Effect of non-uniform heat source on MHD heat transfer in a liquid film over an unsteady stretching sheet", International Journal of Non-Linear Mechanics, vol. 44, no. 9, (2009), pp. 990-998.

[13] N.F.M. Noor, O. Abdulaziz and I. Hashim, "MHD flow and heat transfer in a thin liquid film on an unsteady stretching sheet by the homotopy analysis method", Int. J. Numerical Methods in Fluids, vol. 63, (2010), pp. 357-373.

[14] M.M. Nandeppanavar, K. Vajravelu, M. Subhas Abel, S. Ravi and H. Jyoti, "Heat transfer in a liquid film over an unsteady stretching sheet", International Journal of Heat and Mass Transfer, (2012), vol. 55, pp. 1316-1324. 
[15] X. Xang, I. Pop and X.C. You, "Flow and heat transfer in a nono-liquid film over an unsteady stretching surface", Int. J. Heat and Mass Transfer, vol. 60, (2013), pp. 646,652.

[16] P.G. Metri, J. Tawade and M.S. Abel, "Thin film flow and heat transfer over an unsteady stretching sheet with thermal radiation, internal heating in presence of external magnetic field", arXiv preprint arXiv: 1603.036642016.

[17] S.U.S. Choi, "Enhancing thermal conductivity of fluids with nanoparticles", In: The proceedings of the 1995 ASME International Mechanical Engineering Congress and Exposition, vol. 66, (1995), pp. 99105.

[18] S. K. Das, S.U. Choi, W. Yu and T. Pradeep, "Nanofluids: Science and Technology", Hoboken: Wiley, (2007).

[19] S. Kakac and A. Pramuanjaroenkij, "Review of convective heat transfer enhancement with nanofluids", Int. Cummu. Heat Mass Transfer, vol. 52, no. 13-14, (2009), pp. 3187-3196.

[20] O.D. Makinde and A. Aziz, "Boundary layer flow of a nanofluid past a stretching sheet with convective boundary conditions", Int. J. Therm. Sci., vol. 50, (2011), pp. 1326-1332.

[21] K. Vajravelu, K. V. Prasad, L. Changhoon, I. Pop and R. A. Van Gorder, "Convective heat transfer in the flow of Ag-water and $\mathrm{Cu}$-water nanofluids over a stretching surface", Int. J. Therm. Sci., vol. 50, (2011), pp. 843-851.

[22] P. Rana and R. Bhargava, "Flow and transfer of a nanofluid over a nonlinearly stretching sheet a numerical study", Commun. Nonlinear Sci. Numer. Simul., vol. 17, (2012), pp. 212-226.

[23] J. Buongiorno, "Convective transports in nanofluids", J. Heat Transfer, vol. 128, (2006), pp. 240-250.

[24] N. Sandeep and C. Sulochana, "Unsteady MHD flow of Cu-water dusty nanofluid over a stretching surface", J. Advanced Physics, vol. 5, no. 3, (2016), pp. 191-198.

[25] D. Pal, "Combined effects of an non-uniform heat source/sink and thermal radiation on heat transfer over an unsteady stretching permeable surface", Commun nonlinear Sci and Numer", Simulat, vol. 16, no. 4, (2011), pp. 1890-1904.

[26] M.G. Reddy, P. Padma and B. Shankar, "Effects of viscous dissipation and heat source on unsteady MHD flow over a stretching sheet”, Ain Shams Engineering Journal, vol. 6, no. 4, (2015), pp. 11951201.

[27] R. Ul Haq, S. Nadeem, Z.H. Khan and N.S. Akbar, "Thermal radiation and slip effects on MHD stagnation point flow of nanofluid over a stretching sheet”, Physica E, vol. 65, (2015), pp. 17-23.

[28] C.H. Chen, "Effect of viscous dissipation on heat transfer in a non-Newtonian liquid film over an unsteady stretching sheet”, J. Non-Newtonian Fluid Mech., (2006), vol. 135, pp. 128-135.

[29] R. Cortell, "Effects of viscous dissipation and radiation on the thermal boundary layer over a nonlinearly stretching sheet", Physics Letters A, vol. 372, (2008), pp. 631-636.

[30] H. Dessie and N. Kishan, "MHD effects on heat transfer over stretching sheet embedded in porous medium with variable viscosity", viscous dissipation and heat source/sink, Ain Shams Engineering Journal, vol. 5, no. 3, (2014), pp. 967-977.

[31] M.M. Nandeppanavar, M. Subhas Abel and K. Vajravelu, "Flow and heat transfer characteristics of a viscoelastic fluid in a porous medium over an ompermeable stretching sheet with viscous dissipation", Int. J. Heat Mass Transfer, (2012), vol. 53, pp. 4707-4713.

[32] N.S. Akbar, S. Nadeem and Z.H. Khan, "Numerical simulation of peristaltic flow of a Carreau nanofluid in an asymmetric channel", Alexandria Engineering Journal, vol. 53, (2014), pp. 191-197.

[33] C.S.K. Raju and N. Sandeep, "Heat and mass transfer in MHD non-Newtonian bio convection flow over a rotating cone/plate with cross diffusion”, J. Molecular Liquids, vol. 215, (2016), pp. 115-126.

[34] C. Sulochana, G.P. Ashwinkumar and N. Sandeep, "Transpiration effects on stagnation point flow of a Carreau nanofluid in the presence of thermophoresis and Brownian motion", Alexandria Engineering Journal. (In press). http://dx.doi.org/10.1016/j.aej.2016.03.031, (2016).

[35] M. Khan, Hashim, M. Hussain and M. Azam, "Magnetohydrodynamic flow of Carreau fluid over a convectively heated surface in the presence of non-linear radiation", J. Magn. Magn. Materials, vol. 412, (2016), pp. 63-68.

[36] H. Oztop and E. Abu-nada, "Numerical study of natural convection in partially heated rectangular enclosures filled with nanofluids", Int. J. Heat Fluid Flow, vol. 29, (2008), pp. 1326-1336.

[37] H. Xu, I. Pop and X. You, "Flow and heat transfer in nano-liquid film over an unsteady stretching surface", Int. J. Heat Mass Transfer, vol. 60, (2013), pp. 646-652. 


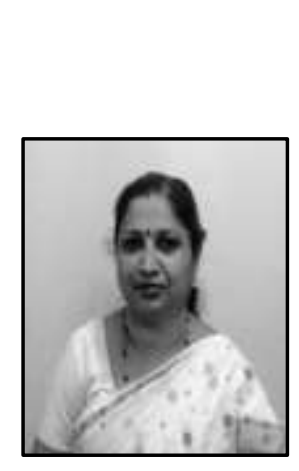

\begin{abstract}
Authors
C. Sulochana, she obtained her M.Sc., and M.Phil. degrees from Gulbarga University, Gulbarga, Karnataka and Ph.D degree from Sri Krishna Devaraya University, Anantapur. She produced 9 Ph.D and 7 M.Phil. degrees. She published more than 85 papers in reputed scientific journals and presented papers in national and international conferences. She handled various prestigious positions at Gulbarga University. At present she is serving as a professor at Department of Mathematics, Gulbarga University, Kalaburagi. Her area of interest is Fluid Mechanics.
\end{abstract}

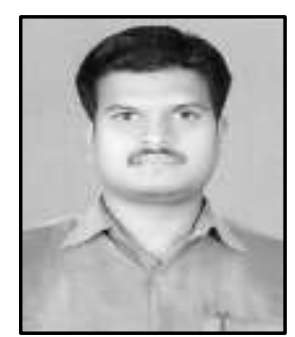

G.P. Ashwinkumar, he obtained his M.Sc. degree from Central University of Karnataka, Gulbarga. Presently he is pursuing Ph.D degree under the guidance of Prof. C. Sulochana in Department of Mathematics, Gulbarga University, Kalaburagi, Karnataka. His area of interest is Fluid Mechanics. He has published several papers in reputed scientific journals and presented papers in national and international conferences. 